Available online on 15.03.2021 at http://ujpr.org
Universal Journal of Pharmaceutical Research
An International Peer Reviewed Journal
Open access to Pharmaceutical research

\title{
PHARMACEUTICAL EVALUATION AND POST-MARKET SURVEILLANCE STUDY OF THREE BRANDS OF LISINOPRIL TABLETS IN SUDAN Fatehalrahman F. Magbool* ${ }^{\circledR}$, Abdrhman Mahmoud Gamil $\triangleright$, Alaa I. M. Ahmed $₫$, Anasseya HA Hassan $\triangleright$, Nagwa J. M. Ali \\ Department of Pharmaceutics, Faculty of Pharmacy, Al-Neelain University, Khartoum, Sudan.
}

\section{ABSTRACT}

Background: Lisinopril is a type of angiotensin-converting enzyme (ACE) inhibitor that used to treat high blood pressure (hypertension) in adults and children. The safety and efficacy of drug products can be assured when their quality is consistent and reproducible. To ensure the requisite quality, pharmaceutical companies are required to test their products during and after manufacturing and at various intervals during the shelf life of the product.

Methods: The aim of this study was to study and evaluate the physicochemical and pharmaceutical parameters in order to confirm the pharmaceutical quality of the generic Lisinopril tablet formulations available in Sudan. Evaluation was done based on the compendia physicochemical and pharmaceutical evaluation parameters. Different brands of Lisinopril 5mg tablets purchased randomly from drug stores, and coded Z, L and A, were assayed for weight uniformity, friability, hardness, disintegration, dissolution rate using standard physical methods, and also the similarity is studied to compare brand of originator to the generic products. Their percentage drug contents were determined using standard UV Spectrophotometric method.

Results: All the brands being studied comply the pharmacopoeial specifications for weight uniformity, friability, disintegration and dissolution. The dissolution profile shows more than $80 \%$ release in 30 minutes. Additionally, all brands should similarity factor above 50\% and therefore to be consider as similar. Quantitatively, all the three brands being tested do complied with the pharmacopoeial specifications for drug content.

Conclusion: Hence this study will serve as a tool in assessing the pharmaceutical quality and to monitor post market quality, safety and efficacy of Lisinopril tablet formulations.

Keywords: Lisinopril, Hypertension, Pharmaceutical quality, Similarity factor, UV Spectrophotometric.

Article Info: Received 4 January 2021; Revised 7 February; Accepted 3 March, Available online 15 March 2021

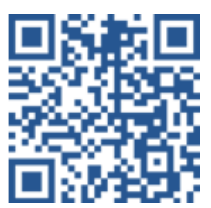

Cite this article-

Magbool FF, Gamil AM, Ahmed AIM, Hassan AHA, Ali NJM. Pharmaceutical evaluation and post-market surveillance study of three brands of lisinopril tablets in Sudan. Universal Journal of Pharmaceutical Research 2021; 6(1):29-33.

DOI: https://doi.org/10.22270/ujpr.v6i1.536

Address for Correspondence

Dr. Fatehalrahman F. Magbool, Department of Pharmaceutics, Faculty of Pharmacy, Al-Neelain University, Khartoum, Sudan. Tel- +966 58215 8608; E-mail: fmagbool@yahoo.com

\section{INTRODUCTION}

With the availability of such large number of brands the health care provider will be in dilemma to select an ideal brand for the cost effective treatment with the same efficacy as that of innovator product. The safety and efficacy of drug products can be assured when their quality is consistent and reproducible from batch to batch. To ensure the requisite quality, pharmaceutical companies are required to test their products during and after manufacturing and at various intervals during the shelf life of the product ${ }^{1}$. Statistically, found that generic drugs are dramatically used, giving rise to a high cost of drug budgets. Since the use of generic drugs is a lower cost than the new products or brands, great savings in health care payment can be made. However, plenty of medical doctors have a doubt of quality of generic drugs and their reliability and to replace a particular drug ${ }^{2,3}$.

Empirical studies found that generic medications have lower therapeutic efficiency and value than branded products even though, they are bio-equivalents of their innovative peers and are produced under good manufacturing practices ${ }^{4}$.Statistics reported by countries in Central and Eastern Europe and some countries from the former Soviet Union showed that manufacturers of imported branded products promote that generic drugs are lower quality compared to the branded one. To obtain approval from FDA for a generic drug, it must match the newly-produced drug in 
active ingredients, strength, dosage form, route of administration, the same usage indications, bioequivalent meet, batch requirements for identity, purity, quality and be manufactured in accordance with the strict standards of FDA's good manufacturing practice regulations required for innovative products ${ }^{5}$. In Sudan as a poor country, the cost is the key factor in defining the patient access to health care. Many people postpone the use of medications required because; of the high cost of branded products. Under these circumstances, locally manufactured medicines are offered as alternative due to their low cost.

Lisinopril $\left(\mathrm{C}_{21} \mathrm{H}_{31} \mathrm{~N}_{3} \mathrm{O}_{5}\right)$ is used to treat high blood pressure (hypertension) in adults and children who are at least 6 years old.

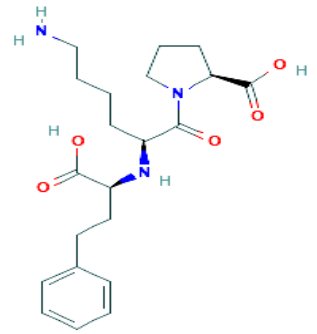

Figure 1: Chemical Structure of Lisinopril.

Lisinopril is a type of angiotensin-converting enzyme (ACE) inhibitor. Like other ACE inhibitors, Lisinopril relaxes and widens the blood vessels. This lowers your blood pressure and makes it easier for your heart to pump blood around your body. This can improve the symptoms of heart failure. In diabetic kidney disease, it helps to protect your kidneys and slows down the disease. It does this by reducing the amount of protein you lose through your kidneys and by reducing high blood pressure. Lisinopril is used to treat high blood pressure. Lowering high blood pressure helps prevent strokes, heart attacks, and kidney problems. It is also used to treat heart failure and to improve survival after a heart attack. Lisinopril starts to work within a few hours to reduce high blood pressure, but it may take a few weeks for it to take full effect ${ }^{6,7}$. Post-market surveillance or monitoring involves all assessments to obtain information of approved marketed product which can be utilized to report if any irregularity in the product to the regulatory body or for product developments and to improve the standards and regulations ${ }^{8}$. Under current Food and Drug Administration (FDA) regulation, a patient may switch from the brand-name drug to a generic drug if the generic shows the same result as that of innovator. Normally it is a general psychology that the quality of the generic are less effective than innovators, presently in many countries a new trend is set to get the generic medicine in place of branded one to lower the national health budget. Due to the fact that different companies manufacture and distribute Lisinopril, there is the risk of purchasing substandard brands which could result in poor clinical outcome and threat to health. In the past years, more than twelve brands of Lisinopril had been registered in Sudan and were imported from India, Syria, Jordan, Europe, USA and locally manufactured. Among this variety, comes a variety in origin of raw material, type of diluents, colouring agents - mostly to distinguish one brand from others, quality assurance measures in these manufactures, consequently the purity of the active constituent in it and of course the price of each product which is significantly different from one brand to another. Therefore, the objective of the present study was carried out for pharmaceutical evaluation and for comparative assessment of the quality for three Lisinopril tablet brands available in the Sudan pharmaceutical market.

Table 1: Feature of selected brands of Lisinopril in Sudan drug market.

\begin{tabular}{lccc}
\hline Country & Brand code & Strength & Expiry date \\
\hline United Kingdom & $\mathrm{Z}$ & $5 \mathrm{mg}$ & $7 / 2022$ \\
Jordon(Oman) & $\mathrm{L}$ & $5 \mathrm{mg}$ & $6 / 2022$ \\
Sudan & $\mathrm{A}$ & $5 \mathrm{mg}$ & $8 / 2023$ \\
\hline
\end{tabular}

\section{MATERIALS AND METHODS}

Three different marketed brands/samples of Lisinopril $5 \mathrm{mg}$ tablets were purchased from community pharmacies (drug store) in Khartoum city, Sudan (Table 1). The samples were properly checked for their drug dose, manufacturing license number, batch numbers, manufacturing and expiry dates. They were coded as Z, L \& A. Chemicals include ethanol, sodium hydroxide, Distilled water, Acetonitrile, and all solvents and chemicals used in the study was analytical grade.

Pharmaceutical Evaluation and Physiochemical Assessment of Lisinopril Tablet Formulations

These are the following pharmaceutical quality control tests were carried out during the study of different marketed brands of Lisinopril $5 \mathrm{mg}$ (USP., 2016) ${ }^{8}$.

\section{Weight Variation Test}

The weight variation test was analyzed by selecting twenty tablets randomly and average weights were determined. Then individual tablet weighed and compared with the average. The requirement met the (USP, 2016); if not more than two tablets differ from the average weight $\pm 5 \%$ and no tablet differs in weight by double that percentage, the tablets will be accepted.

\section{Hardness Test}

The resistance of tablets to shipping or breakage under conditions of storage, transportation, and handling before usage depends on its hardness. The hardness of tablet of each formulation was measured by Monsanto hardness tester. The hardness was measured in terms of $\mathrm{kg} / \mathrm{cm}^{2}$

Friability Test

Friability is the measure of tablet strength. Erweka Friabilator was used to perform the test. Twenty tablets were weighed accurately and placed in the tumbling 
apparatus that revolves at $25 \mathrm{rpm}$ dropping the tablets through a distance of six inches with each revolution. After 4 min., the tablets were weighed and the percentage loss in tablet weight was determined. Conventional compressed tablets that lose less than 0.5 to $1.0 \%$ of their weight are generally considered acceptable.

\section{Thickness Test}

Thickness was calculated using Vernier caliper. Ten tablets from each formula were used, and average values were calculated.

\section{Disintegration Test}

The disintegration times of six randomly selected tablets was determined in distilled water at $37 \pm 0.5^{\circ} \mathrm{C}$ using an Erweka tablet disintegration tester (Type ZT3/1, Heusenstamm, Germany). Until no particle remained on the basket of the system. The time taking for each of the six tablets tested in each of the brand was recorded.

\section{Dissolution Test}

The dissolution tests were carried out using the basket method according to US Pharmacopoeia (USP) guidelines. Dissolution media was prepared that contains $0.1 \mathrm{~N}$ of hydrochloride. All apparatus was washed and dried. Beakers in dissolution tester were filled by $0.1 \mathrm{~N}$ hydrochloride. Temperature was adjusted to $37^{\circ} \mathrm{C}$ and Device was adjusted to 50 revolutions per minute for 30 minute. Six tablets of each brands were put inside rapidly. Five $\mathrm{ml}$ were taken from each beaker in time 5, 10, 15, 20, 25, 30 minute and completed to $50 \mathrm{ml}$ of $0.1 \mathrm{~N}$ hydrochloride. After that was read in UV at wavelength $215 \mathrm{~nm}$, and determine the absorbance of the solutions, using blank to zero the spectrophotometer calculate the percentage of Lisinopril dissolved.

\section{Uniformity test}

Diluent was prepared by weighing $2.7 \mathrm{gm}$ of monobasic potassium phosphate and grinded by mortar and pestle then taken to beaker. Then dissolved in $800 \mathrm{ml}$ of distilled water. The $\mathrm{pH}$ was measured by $\mathrm{pH}$ meter and adjusted to $(\mathrm{pH}=4)$ by addition of phosphoric acid. Six tablets from each brand of Lisinopril five $\mathrm{mg}$ were weighted and grinded by mortar and pestle. From the powder a definite weight that contain $20 \mathrm{mg}$ of Lisinopril was taken to volumetric flask and completed to $100 \mathrm{ml}$ using diluents of monobasic potassium phosphate to obtain solution contain concentration of $(0.2 \mathrm{mg} / \mathrm{ml})$. Mixture was filtered by filter paper to obtain clear solution. After that each mixture of different brands were read in UV at wavelength 215 $\mathrm{nm}$ the result was documented.

\section{Statistical Analysis}

The results obtained are expressed as a mean \pm standard deviation calculated using Microsoft excel 2010 software. Statistical analysis was performed using SPSS version 20.0 for windows (SPSS Inc. Sep 2011).

\section{RESULTS AND DISCUSSION}

The quality parameters associated with pharmaceutical products are always assured through quality control methods of analysis. Quality procedures are pertinent to ensuring that drugs or medicines reaching patients are safe, efficacious and potent ${ }^{10}$. Strict adherences to Good Manufacturing Practice (GMP) during the granulation and compression stages ensure tablet weight uniformity. All the brands passed the friability test as they all had a weight loss of less than $1 \%$ as shown in Table 2. Good friability property ensures tablets do not chip during transportation as a result of abrasion and is an evidence of good finished product. All the brands tested disintegrated within the prescribed limit of 15 minutes (Table 2). The presence of suitable disintegrants in adequate proportions ensures the production of tablets which are free from disintegration problems ${ }^{11}$. The disintegration time of all brands may definitely indicate that the drug would be released into the dissolution medium easily. Tables 2 represent the dissolution of the different brands of Lisinopril, all the brands passed the US Pharmacopoeia (2016) specifications ${ }^{8}$. The dissolution of drug from oral solid dosage forms is a necessary criterion for determination of drug bioavailability.

Table 2: Results of physiochemical quality control tests.

\begin{tabular}{ccccccc}
\hline Brand & $\begin{array}{c}\text { Weight } \\
\text { Variation (\%)* }\end{array}$ & Thickness & $\begin{array}{c}\text { Friability } \\
(\boldsymbol{\%}) *\end{array}$ & Hardness* & $\begin{array}{c}\text { Disintegration } \\
\text { time (Minutes) }\end{array}$ & $\begin{array}{c}\text { Dissolution \% } \\
\text { in 30 minute }\end{array}$ \\
\hline $\mathrm{Z}$ & $0.85 \pm 0.003$ & 0.30 & $0.14 \% \pm 0.25$ & $4.06 \pm 0.18$ & 0.58 & 92.5 \\
$\mathrm{~L}$ & $3.3 \pm 0.03$ & 0.30 & $0.17 \% \pm 0.55$ & $4.01 \pm 0.02$ & $1: 20$ & 89.3 \\
$\mathrm{~A}$ & $3.28 \pm 0.09$ & 0.40 & $0.49 \% \pm 0.36$ & $3.9 \pm 0.17$ & $5: 10$ & 85.7 \\
\hline
\end{tabular}

Table 3: Similarity and difference factors of Lisinopril $(\mathrm{N}=6)$.

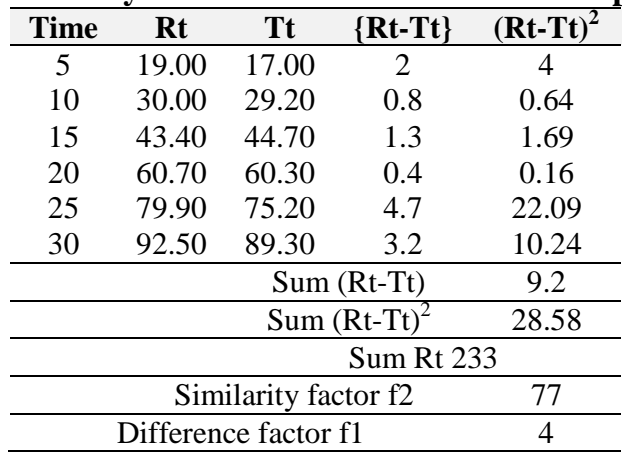


Table 4: Similarity and difference factors of Lisinopril.

\begin{tabular}{ccccc}
\hline Time & Rt & Tt & (Rt-Tt $\}$ & ${\text { (Rt-Tt })^{\mathbf{2}}}$ \\
\hline 5 & 19.00 & 13.70 & 5.3 & 28.09 \\
10 & 30.00 & 25.20 & 4.8 & 23.04 \\
15 & 43.40 & 42.00 & 1.4 & 1.96 \\
20 & 60.70 & 55.80 & 4.9 & 24.01 \\
25 & 79.90 & 70.20 & 9.7 & 94.09 \\
30 & 92.50 & 85.70 & 6.8 & 46.24 \\
\hline \multicolumn{4}{c}{ Sum (Rt-Tt) } & 26.1 \\
\hline \multicolumn{4}{c}{ Sum (Rt-Tt $)^{2}$} & 171.19 \\
\hline \multicolumn{4}{c}{ Sum Rt } & 233 \\
\hline \multicolumn{4}{c}{ Similarity factor f2 } \\
\hline \multicolumn{4}{c}{ Difference factor f1 } \\
\hline
\end{tabular}

Reference $=$ Zestril, $\mathrm{N}=6$

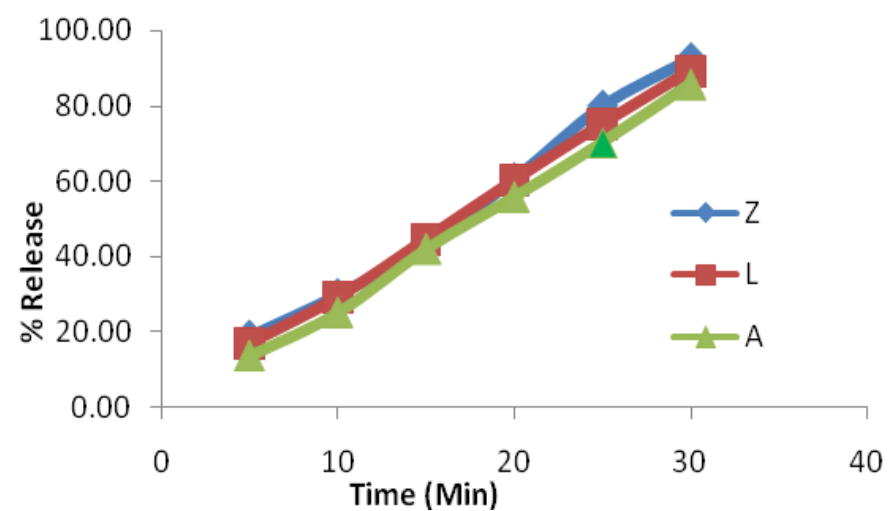

Figure 2: Dissolution profile of the studied brands.

It serves as useful tool in assessing the probable in vivo performance of a drug as well as in identifying unacceptable and substandard drug products ${ }^{12}$.

\section{F Factor}

The similarity model independent method uses (f1) which is the difference factor that calculates the percent $(\%)$ between the two curves at each time point and is the measurement of the relative error between the two curves ${ }^{13}$.

$\mathrm{Rt}=$ is the dissolution value $\%$ of the reference at time $\mathrm{t}, \mathrm{Tt}=$ is the dissolution value $\%$ of the test at time $\mathrm{t}$. The similarity factor (f2) is a logarithmic reciprocal square root transformation of the sum of squared error and is the measurement of the similarity percent (\%) dissolution between the two curves ${ }^{13}$. The similarity is used to compare brand of originator to the generic products. FDA defines generics as copies of brand name drugs and is the same as those brand name drugs in dosage form, safety, strength, route of administration, quality, performance characteristic and intended use.

\section{F1 Difference factor}

\section{F2 Similarity factor}

$$
f_{1}=\left\{\left[\Sigma\left|R_{t}-T_{t}\right|\right] / \Sigma R_{1}\right\} \times 100=15.42
$$

$$
f_{2}=50 \log \left\{\left[1+\frac{1}{n} \sum_{n=1}^{n}\left(R_{t}-T_{t}\right)^{2}\right]^{-0.5} * 100\right\}
$$

Sample should have similarity factor above $50 \%$ to be consider as similar and having difference factor lower than $15 \%$ to be considered as on differences. From the results L brand has similarity factor 77 so consider similar to innovator and have difference factor equal to 4 consider there is no difference between it and innovator, also A brand give similar factor equal to 59 indicating that it is also similar to innovator but in lower percent. It has a difference factor equal to 11 indicating that it has no difference from innovator.

Quantitative analysis using UV spectrophotometric method has been reported for the chemical content determination of various drugs in official monograph. The method was able to detect an apparently fake brand of Lisinopril tablets.

Table 5: Content percent of three Lisinopril brands.

\begin{tabular}{ccc}
\hline Sample & Absorbance & \% content \\
\hline $\mathrm{Z}$ & 3.49 & 104.5 \\
$\mathrm{~L}$ & 3.41 & 102 \\
$\mathrm{~A}$ & 3.60 & 108 \\
\hline \multicolumn{3}{c}{ Standard Absorbance $=3.328$}
\end{tabular}

UV method is widely used in determining the identity, purity, efficacy, stability and content of drugs. This method is still widely used in official compendial assays, because of their robustness, cheapness and capability of high precision. According to the United State Pharmacopeia (USP), a Lisinopril tablet should contain not less than $90 \%$ and not more than $110 \%$ of Lisinopril. The results (Table 5) of the active content of products of the three brands in this study were within the limits and comply with the USP specifications ${ }^{8}$, which are in parallel with other studies which demonstrated brand-brand equivalence with the innovator product ${ }^{14,15}$. 


\section{CONCLUSION}

Hence this study will serve as a tool in assessing the pharmaceutical quality and to monitor post market quality, safety and efficacy of Lisinopril tablet formulations. The use of substandard Lisinopril tablets in treatment would result in sub-therapeutic levels of the drug in patients, leading to treatment failure and also possible development of drug toxicity. Therefore, there is a need for drug regulatory bodies in Sudan to be vigilant and undertake routine assessment of the quality of Lisinopril products on the market in order to flush out and to overcome developing of counterfeit and substandard products.

\section{AUTHOR'S CONTRIBUTION}

All authors have worked equally for this work.

\section{ACKNOWLEDGEMENTS}

The authors are thankful to wish to Azal Industries, Khartoum, Sudan, for providing the gift sample of Lisinopril (standard).

\section{CONFLICT OF INTEREST}

No conflict of interest associated with this work.

\section{REFERENCES}

1. Chow SJ. J Drug Information 1997; 31:1195-1201. https://doi.org/10.1177\%2F009286159903300215

2. Biswas R, Chatterjee P, Mundle M. Prescribing habits of physicians in medical college, Calcutta. Indian J Community Med 2000; 25: 161.

3. Hassali MA, Shafie AA, Awaisu A, Ibrahim MI, Ping CC, Jamshed S. Physicians' views on generic medicines: A narrative review. J Generic Med. 2010; 7:30-9. https://doi.org/10.1057/jgm.2009.32

4. Shrank WH, Cox ER, Fischer MA, Mehta J, Choudhry NK. Patients' perceptions of generic medications. Health Aff (Millwood) 2009; 28: 546-56. https://doi.org/10.1377/hlthaff.28.2.546

5. Dighe SV. A review of the safety of generic drugs. Transplantation Proceedings 1999; 31 (Suppl 3A), 23S4S. https://doi.org/10.1016/s0041-1345(99)00109-8

6. Till AE, Dickstein $\mathrm{K}$, Aarsland, et al. The pharmacokinetics of Lisinopril in hospitalized patients with congestive heart failure. Br J Clin Phannacol 1989; 27: 199-204.

https://dx.doi.org/10.1111\%2Fj.1365-

2125.1989.tb05351.x

7. Neubeck M, Fliser D, Pritsch M, et al. Pharmacokinetics and pharmacodynamics of Lisinopril in advanced renal failure: consequence of dose adjustment. Bur J Clin Phannacol; 1994; 46: 537-43. https://doi.org/10.1007/bf00196112

8. Alsaifi A, Ali A. Quality assessment of different brands of paracetamol tablets in Yemeni market. Universal J Pharm Res 2018; 3(4): 39-43. https://doi.org/10.22270/ujpr.v3i4.182

9. United States Pharmacopeia and National Formulary (USP 41-NF 36). Rockville, MD: United States Pharmacopeial Convention 2016; 277:674, 731.

10. Magbool FF, Ibrahim ME. Pharmaceutical evaluation and quality assessment of artesunate tablets available in pharmacies in Sudan. World J Pharm Med Res 2018;4(1):39-44.

11. Jantratid E, Janssen N, Reppas C, Dressman JB. Dissolution media simulation conditions in the proximal human gastrointestinal tract: an update. Pharm Res 2008; 25: $1663-1676$ https://doi.org/10.1007/s11095-008-9569-4

12. Jaman M, Chowdhury AA, Rana AA, Masum SM, Ferdous T, Rashid MA, Karim MM. In vitro evaluation of ciprofloxacin hydrochloride. Bangladesh J Sci Ind Res 2015; 251-256. https://doi.org/10.3329/bjsir.v50i4.25833

13. Guidance for Industry, Dissolution testing of immediate release solid dosage forms. US department of Health and Human Services, FDA, Centre for Drug Evaluation and Research, August, Rockville, MD 20857, 1997.

14. Olaniyi AA, Babalola CP, Oladeinde FO, Adegoke AO. Eds. Towards better quality assurance of drugs: proceedings of $4^{\text {th }}$ National Workshop, Dept. of Pharmaceutical Chemistry, University of Ibadan, Ibadan. 2001; 59-60, 70-3.

15. Al-Tahami K. A Comparative quality study of selected locally manufactured and imported medicines in Yemeni Market. Yemeni J Med Sci 2010; 8-13. 